\title{
REFLEXÕES ACERCA DO LUGAR DOS ESTUDOS DE VERTENTE FORMAL DO \\ CONTO DE FADAS NO CONTEXTO DO SISTEMA LITERÁRIO E FACE AOS DESENVOLVIMENTOS ATUAIS DA ÁREA DE LIJ
}

FORMALIST FAIRY TALE STUDIES WITHIN THE

LITERARY SYSTEM AND CURRENT DEVELOPMENTS OF CHILDREN'S LITERATURE RESEARCH

André Luiz Ming Garcia' 


\section{INTRODUÇÃO}

O objetivo inicial que impulsionou a produção deste trabalho foi o desejo de apresentar ao público brasileiro uma tradução do ensaio "Fairy tale is form, form is fairy tale", publicado originalmente em 2009 pela escritora e pesquisadora norte-americana Kate Bernheimer, como parte de uma coletânea de textos editada pela Tin House Books que se concentra em ensaios críticos sobre arte elaborados por artistas-pesquisadores.

Meu supramencionado desejo tem suas origens em uma série de fatores: primeiramente, minha predileção por ouvir atentamente as vozes de criadores de arte que também elaboram reflexão criteriosa de cunho acadêmico acerca de objetos análogos aos que engendram, em uma forma híbrida de textos que acomodam rigor no raciocínio apresentado e estilo de escritura semi-literário.

De fato, a natureza multifacetada, híbrida, insubordinada e desafiadora das artes contemporâneas requer uma multiplicidade de olhares que sobre elas se debrucem, olhares esses que necessitam reformular-se constantemente de modo a captar os novos (e sempre em processo de vir-a-ser) procedimentos estéticos e gestos comunicativos em artes. Assim, além de requererem a inter, multi e transdisciplinaridade, esses objetos também reclamam distintas perspectivas de análise que auxiliem-nos na contemplação da infinidade de aspectos passíveis de perscrutação e de recorte quando da fruição crítica de tais obras.

Em segundo, mas não menos importante lugar, o ímpeto de produzir esta tradução deveu-se ao entusiasmo com que meus alunos de graduação costumam ler o ensaio de Bernheimer, fascinados pelo caráter sucinto e agudo de suas observações, ilustradas por ricos exemplos e verdadeiras sugestões de leituras que expandem nosso próprios repertórios, as quais, em breves páginas, oferecem-nos uma original e perspicaz síntese da teoria formal do conto de fadas elaborada por Max Lüthi há pelo menos sete décadas e que, mediante a escrita de Bernheimer, vê-se, desta feita, além de mais enxuta, desejavelmente atualizada, em gesto necessário de revisão da crítica literária antecedente.

Deste modo, ao passo em que atualiza elementos de uma obra seminal por vezes taxada de "antiga", recupera seu valor imensurável e ainda insuperado no conjunto de 
textos críticos dedicado ao mesmo tema e sob perspectiva correlata. Esse entusiasmo expresso por parte dos alunos tem-se visto acompanhado de ricas discussões e consideráveis e satisfatórias aferições, por minha parte, de seu aprendizado. Além disso, a abordagem de Bernheimer do entendimento da forma do conto de fadas como um modo de compreensão de suas técnicas de criação é apresentada pela autora, neste ensaio, não como um manual, mas como um instrumental de apoio para todos os escritores que desejem criar contos de fadas ou obras de outros gêneros, como romances e novelas, que as contenham, partindo de sua compreensão sistêmica. Isso vale também para todos os nossos alunos de Literatura que desejam - e frequentemente expressam em aula esse desejo - aventurar-se pela escrita de narrativas maravilhosas, de fantasia e todos os tipos de fabulações aos moldes dos contos de fadas ou neles inspiradas.

Finalmente, faz-se-me imperioso ressaltar o fato de que os estudos literários que focalizam a forma das textualidades poéticas, ou, caso se prefira, estudos literários de talhe formalista, embora sempre valorados dentro de certos grupos, têm-se visto relegados a um segundo ou mesmo terceiro plano face às transformações dos interesses investigativos na área de Literaturas, com foco especial, aqui, aos estudos de literatura infantil e juvenil (doravante, LIJ). Bem verdade é que tais transformações nada mais são do que as adaptações do olhar atento às próprias mudanças $(\mathrm{d} / \mathrm{n}) \mathrm{o}$ mundo-sociedade-cultura em que vivemos, mudanças essas que, ao fim e ao cabo, nada mais parecem ser além de reajustes de enfoque(s) ao lidarmos com o mundo e conosco mesmos, tanto pelo já referido fato de que novas obras de arte a surgir conclamam novos olhares e olhares renovados, como também, assim como veremos mais adiante, pelo consenso cada vez mais crescente no âmbito das humanidades de que muitas questões anteriormente vistas como naturais provavelmente não passem de construtos sociais e culturais, entre elas as que tangenciam nossos entendimentos coletivos de cultura e natureza (fronteira há décadas já esboroada pela semiótica peirciana), de sexualidade e gêneros, de infância e de nosso papéis em uma estrutura social de hierarquias tão silenciosas quanto contundentes, para mencionar algumas poucas mas deveras relevantes no contexto deste artigo.

Assim, o desejo anunciado de produzir uma tradução ao português do texto de Bernheimer pretende corresponder aos motivos ora expostos e incentivar, de algum 
modo, novos avanços nos estudos literários de vertente mais formalista, sem que, com isso, esteja-se propondo um abandono ou preterimento das outras inclinações investigativas existentes nos estudos da literatura e das artes, cujos artefatos, como já mais de uma vez aqui dito, requerem pluralidade e diversidade de olhares, métodos e pensares. Para além disso, é almejado o estímulo à criação, por parte de novos escritores, quiçá ainda na fase de armazenarem seus esboços na gaveta, de contos de fadas e narrativas a eles análogas ou relacionadas.

Entregar tal tradução sem contextualizá-la na esfera dos estudos contemporâneos de literatura, com foco especial na LIJ, e nos liames do sistema literário do qual fazem parte pareceu-me, entretanto, opção pouco qualificada. Deste modo tentarei, nos parágrafos que seguem, abordar os dois temas ora mencionados em ordem reversa e, por fim, apresentar a autora e seu texto, concluindo com a anunciada tradução de seu ensaio.

\section{O SISTEMA LITERÁRIO E OS ESTUDOS ACERCA DO CONTO DE FADAS}

Antonio Candido, em seu influente livro A formação da literatura brasileira: momentos decisivos, 1750-1880 (2006 [1975]), busca circunscrever os caminhos de uma "história dos brasileiros no seu desejo de ter uma literatura", considerando, como não poderia deixar de ser a partir de tal perspectiva, as obras literárias como parte de um sistema dentro do qual se articulam entre seu autor e seu(s) leitor(es). Apesar de possuir familiaridade com esta obra, preferirei, aqui, remeter a um recorte de aspecto central seu realizado por Marisa Lajolo em artigo de notória expertise elaborado a partir de uma apresentação feita pela estudiosa por ocasião do simpósio "Monteiro Lobato: texto e contexto" durante o XII Congresso Internacional da Associação Brasileira de Literatura Comparada (ABRALIC) em julho de 2011. A escolha por este caminho deve-se sobremaneira ao pertinente encaixe que ela engendra de aspectos pontuais do ideário de Candido no campo da LIJ, ainda que com objetivos finais distintos daqueles que motivam a escritura do presente texto.

Assim, a partir de reflexões contidas nesta obra, Marisa Lajolo (2011), não por 
acaso ex-orientanda do mestre Candido e hoje detentora de voz de autoridade em estudos literários, com destaque para a LIJ, recupera-lhe os conceitos gerais contextualizando-os no âmbito de problemáticas relacionadas à recepção hodierna de obras literárias de tempos pregressos, um intrincado processo que, se acaso mal conduzido, consiste em convite ao anacronismo. No caso deste texto específico, versa acerca de polêmicas a respeito de aspectos da recepção do texto lobatiano Caçadas de Pedrinho nos dias de hoje. Aqui, recuperarei, entretanto, o seguinte trecho de seu artigo, que buscarei contextualizar no âmbito dos estudos acerca do gênero conto de fadas. Segundo Lajolo,

tradicionalmente, os estudos literários parecem privilegiar as categorias-vértice. Com efeito, vertentes de extração formalista e retórica privilegiam a obra, vertentes de cunho psicanalista ou biográfico privilegiam o autor e vertentes contemporâneas inspiradas na Estética da recepção privilegiam leitores. Pesquisas mais recentes sobre a História da Leitura (área ampla que recobre a História do livro e de livros, do leitor e de leitores, de autores e de editores) apontam para a importância das mediações entre autores e obras, entre obras e públicos e entre autores e público (LAJOLO, 2011, n.p, sic).

Transpondo estas considerações para o campo do conto de fadas, podemos alocar, deste mesmo modo tripartite, os estudos que tradicionalmente compõem o arcabouço crítico a respeito desta temática. Aqui, entretanto, estaremos considerando, tendo em vista o público-alvo almejado deste escrito, tendências acadêmicas brasileiras na abordagem do conto de fadas, uma vez que, em nível internacional, observamos o predomínio de orientações investigativas dessas mesmas narrativas bastante díspares das que registramos nos trópicos, entre elas:

- A tendência alemã (considerando-se, aqui, a origem dos Grimm) de enquadramento do assunto contos de fadas nas áreas de Estudos Sociais e Culturais e não exatamente literários;

- A segunda e mais tímida tendência alemã de enquadramento dos contos de fadas, quando ocorre no campo dos estudos de literatura, fora do recorte acadêmico LIJ; 
- A tendência internacional e pronunciadamente anglo-saxã de estudos de LIJ focados em questões educacionais e de recepção infantil;

- A crescente preocupação dos estudos internacionais de LIJ com releituras e reinterpretações do cânone de cunho crítico e questionador face a construtos socioculturais e convenções passadas dos gêneros literários e, entre outros fatores, seus componentes hoje considerados politicamente incorretos.

Apesar deste contexto internacional, os estudos brasileiros atuais sobre o conto de fadas e os estudos estrangeiros que mais fortemente ecoam e reverberam nestas terras encaixam-se, ainda, na categorização tripartite de Lajolo baseada nas considerações de Candido a respeito do sistema literário. Deste modo e a partir disso, aqui temos (não exaustivamente):

- Escritos críticos de tradição formalista e retórica: aqui, destacam-se de modo seminal, na primeira metade do século XX, os textos de Vladimir Propp, Max Lüthi e André Jolles, entre outros, cada qual versando sobre recortes próprios de questões formais específicas do gênero;

- Estudos críticos de cunho psicanalítico e biográfico: no primeiro subgrupo, temos os influentes escritos de Bruno Bettelheim, sobretudo, assim como de Marie-Louise von Franz; no segundo, grande volume de estudos biográficos sobre os irmãos Grimm e seu ofício enquanto filólogos, linguistas, pesquisadores e escritores, oriundos, estes últimos, em grande parte, da Alemanha;

- Estudos críticos que versam a respeito da recepção do conto de fadas: tendência atual que parece seduzir grande número de pesquisadores preocupados com os desdobramentos das leituras contemporâneas de contos de fadas literários originários de finais do século XVII (Perrault, entre outros) ou início do XIX (Grimm, sobretudo), frequentemente inseridos na interseção literatura-(psico)pedagogia.

Esta divisão não se pretende, contudo, estanque. Vários textos críticos que versam a respeito da LIJ imbricam-se entre mais de uma tendência ou conformam-se no 
contexto de uma metodologia já previamente trilhada pelo pesquisador, como os estudos de perfil culturalista e de historiografia literária crítica empreendidos sobre este gênero por Nelly Novaes Coelho em constante contextualização das obras de ficção analisadas no marco de uma leitura dos desenvolvimentos da sociedade e da cultura, até o momento ainda influentes no Brasil. Observam-se, também, tendências atuais de focalizar contos de fadas contemporâneos e/ou reinvenções contemporâneas de contos de fadas literários tradicionais considerando questões prementes e concernentes às problemáticas da intertextualidade, da metaficção e da intermidialidade, relevando-se, junto a esta última, o caráter não apenas semioticamente híbrido da LIJ, mas também seu diálogo incessante com todas as demais linguagens artísticas e formas de conhecimento.

Este aglomerado de orientações investigativas e analíticas, com seus riquíssimos meandros, vária vez intersemióticos e intermidiáticos, bem assim pondo em diálogo a literatura com outras áreas do saber, em exercícios sofisticados de literatura comparada, pode intimidar ou fazer parecer ortodoxos ou pouco criativos os estudos literários de orientação mais formalista. Para o olhar mais superficial ou desatento, o foco no texto em si e nos desdobramentos de sentidos gerados pela sintaxe dos signos articulados exclusivamente no seio da obra, desconsiderando o humano que a gera e o humano que a co-constrói mediante a leitura poderia parecer, além de pouco glamouroso, desumanizador.

Malgrado esta possibilidade, o olhar atento tenderá a reconhecer tal foco como rudimento sofisticado de exalçamento da obra que, ao final, tende a revalorizar todos os elementos integrantes do sistema literário. Assim, e de modo a enfatizar as benesses de uma abordagem formalista e objetiva do texto literário (que não se pretende exclusiva ou excludente) diante dos compromissos de objetividade e empirismo da pesquisa científica, afirmava Lucrécia D’Alessio Ferrara:

A consciência de que a obra literária é um produto organizado segundo alguns princípios afastou, do cenário da crítica contemporânea, as especulações subjetivo-interpretativas sobre uma mística da criação literária e valorizou a pesquisa objetiva e racional do processo de construção da obra [mediante] técnicas de descrição e denomi- 
nação cada vez mais rigorosas e mais próximas da ciência, sem se afastar, contudo, daquela liberdade, própria da ciência, que impõe as transformações das técnicas utilizadas, sempre que solicitadas pela natureza do próprio fenômeno pesquisado (FERRARA, 1978, p. 21).

Afastando ideias vagas a respeito de um possível reducionismo das abordagens formalistas de análise literária, a autora também destaca a possibilidade de o crítico assim "penetrar, pouco a pouco, no emaranhado de linhas que situam o jogo dos significantes até chegar à configuração plural dos significados" (p. 21-22), de modo a que se contemple a obra como "campo de possibilidades" (p. 22).

Se considerarmos essas asserções no já há muito e por muitos anunciado contexto de crise na literatura que nos tem levado ao que alguns já denominam uma sociedade pós-literária (COSSON, 2016), caracterizada por mudanças nas relações tanto entre as artes entre si quanto entre os leitores e as linguagens e obras ("mundos simbólicos", nas palavras de Cosson), observaremos que a compreensão dos sentidos engendrados dentro do texto literário e a partir dos signos articulados no seio dele, sobretudo daquele primordial que serve de base e inspiração para a profusa e incessante criação de tantas outras textualidades a ele intertextualmente ligadas como o conto de fadas, permitir-nos-á compreender com muito mais pronunciado êxito as vicissitudes não apenas de todas essas novas textualidades que não cessam de surgir, como também dos outros vértices do sistema: o processo original de criação e o processo de recepção, que também é, a seu modo, processo de criação.

É nesse sentido que cumpre valorizar o esforço e a sagacidade de Bernheimer ao trazer para o século XXI as reflexões fundamentais de Max Lüthi acerca do conto de fadas com base em suas características formais. Essa revalorização de Lüthi faz especial sentido se considerarmos críticas contemporâneas a uma suposta desatualização das reflexões de Lüthi que baseiam-se estereotipicamente na irrefutável antiguidade de seus textos e não em uma suposta antiguidade de suas ideias, a qual nenhum crítico conseguiu demonstrar com algum estofo. Apesar disso, o volume de classificações de Lüthi, constituintes do cerne de seus livros, qualificados pela própria 
Bernheimer como "incríveis, repetitivos e poéticos" ${ }^{2}$ clamou, na atualidade, por uma modernização de sua expressão de maneira mais enxuta e adaptada à análise e leitura de obras posteriores ao estudioso suíço e que, como tais, requerem certas reconduções de olhar.

Qual seria, porém, a competição encarada pelos estudos do conto de fadas de corte formal(ista) em face das tendências ou interesses contemporâneos dos estudos acadêmicos de literatura, de modo geral, e de LIJ, de maneira específica? Com o intuito de prosseguir com as presentes reflexões neste rumo, visitarei, no item seguinte, o criterioso e bem informado balanço que nos apresentou em 2016 Maria Nikolajeva das tendências recentes na pesquisa de literatura infantil, as quais, segundo a estudiosa, promovem um "retorno ao corpo".

\section{ESTUDOS HODIERNOS DE TEXTUALIDADES PRIMORDIAIS E OUTRAS DA LIJ}

Ao tratar dos rumos correntes da pesquisa em LIJ, Nikolajeva (2016) concentra-se inicialmente em nomear a proeminência dos interesses investigativos mais explorados na pesquisa internacional em LIJ da década de 1990, que se concentrava nas seguintes áreas ou temáticas:

- visões (e, por consequência, representações) de infância como construções sociais;

- visões de infância que perpassam a produção de LIJ como projeções e, assim, representações do adulto autor (i. e., como questões de interioridade adulta);

- questões de gênero e identidade de gênero;

- questões étnicas e raciais;

- questões de orientação sexual;

\section{Negrito meu.}


- como consequência ou mesmo gerando a tessitura dessas questões, discussões concernentes a hierarquias sociais e sistemas opressivos.

Como característica mais proeminente da pesquisa internacional em LIJ mais recente, Nikolajeva ressalta uma virada rumo a questões de materialidade e corporeidade, quais sejam, entre outras:

- questões relativas às pessoas com deficiência;

- focalização de questões concernentes aos corpos infantis;

- questões concernentes ao meio ambiente em sua materialidade.

Ainda premente parece ser o que se relaciona às:

- questões relativas ao caráter do que é humano, humanidade e o pós-humano.

Enquanto as reflexões dedicadas aos temas elencados no escopo dos estudos noventistas baseavam-se sobremaneira em teorias culturais, a pesquisa mais atual parece calcar-se cada vez mais em arcabouços críticos como aqueles advindos da ecocrítica, do pós-humanismo, de estudos sobre deficiência e da crítica cognitiva. $\mathrm{O}$ parágrafo seguinte do texto da pesquisadora de Cambridge subsume os termos dessa virada material:

[...] gradualmente ocorreu uma mudança tangível de atitude, conhecida como virada material. De repente, colegas e alunos estão trabalhando em novos tópicos, como ecocritítica (Dobrin e Kidd; Curry), identidades relacionadas ao lugar (Cutter-Mackenzie et al.), estudos sobre animais (Jaques), estudos sobre deficiência (Keith, Aveling) e poética cognitiva (os 'Schemas and Scripts' de Stephen, Kümmerling-Meibauer, Trites). Eles exploram mapas na literatura infantil (Pavlik), o aspecto físico da paisagem (Carroll), objetos e artefatos, incluindo casas de bonecas (Chen) e moda (Vaclavik), economias ocultas, punição corporal e suicídio assistido, apenas para citar alguns exemplos. O denominador comum de muitos novos campos interdisciplinares é o foco na materialidade. No entanto, essa tendência conspícua não apenas nos leva de volta ao essencialismo, 
mas também reflete a complexidade, pluralidade e ambiguidade de nossa compreensão da infância e sua representação na ficção produzida e comercializada para o público jovem. Esses estudos recentes exploram com mais detalhes a relação complexa entre fenômenos perceptíveis e suas representações na ficção infantil; entre o corpo físico e seu retrato ficcional imaterial, lingüístico; entre o lugar físico e o fictício; entre a identidade humana e a identidade enigmática e inexistente de personagens fictícios feitos exclusivamente de palavras (NIKOLAJEVA, 2016, p. 133) ${ }^{3}$.

No Brasil, observa-se que as tendências temáticas internacionalmente difundidas nos anos 1990 parecem florescer mais nestas primeiras décadas do século XXI, quando testemunhamos a ascensão em prestígio dos estudos de gênero e feministas, da teoria queer e da teoria racial crítica e, não rara vez, um pano de fundo de orientação marxista e perspectivas pós-coloniais, bem como um correspondente alinhamento com posicionamentos político-ideológicos de cunho mais progressista.

Assim, percebe-se que a tendência dominante na atualidade seria a de enfocar elementos integrantes das textualidades (obras) sempre em profunda relação com os eixos 1 e 2 do esquema de Lajolo com base em Candido aqui reproduzido e adaptado

3 Tradução minha. Trecho original em inglês: “[...] gradually a tangible change in attitude has occurred, referred to as the material turn. Suddenly colleagues and students are working on new topics such as ecocriticism (Dobrin and Kidd; Curry), place-related identities (Cutter-Mackenzie et al.), animal studies (Jaques), disability studies (Keith; Aveling) and cognitive poetics (Stephens 'Schemas and Scripts'; Kümmerling-Meibauer; Trites). They explore maps in children's literature (Pavlik), the physicality of landscape (Carroll), objects and artefacts, including dollhouses (Chen) and fashion (Vaclavik), hidden economies, corporal punishment and assisted suicide, just to give a few examples. The common denominator of many new cross-disciplinary fields is their focus on materiality. However, this conspicuous trend does not simply take us back to essentialism, but also reflects the complexity, plurality and ambiguity of our understanding of childhood and its representation in fiction produced and marketed for young audiences. These recent studies explore in more detail the complex relationship between perceptible phenomena and their representations in children's fiction; between the physical body and its immaterial, linguistic fictional portrayal; between physical and fictional place; between human identity and the enigmatic, non-existing identity of fictional characters made exclusively of words" (Tradução nossa). 
à abordagem específica do conto de fadas, registrando-se, assim, um destaque mais recente para as questões de corporeidade e materialidade (questões concernentes à existência física das crianças e do meio ambiente, antes negligenciadas nas pesquisas sobre LIJ) que consistem, de fato, no foco principal do artigo de Nikolajeva (2016).

A luz lançada por Nikolajeva sobre essas tendências distintivas da pesquisa mais recente na área não significa, entretanto, que as questões sociais tenham exatamente sido relegadas a um plano secundário na pesquisa internacional. É notória a ênfase que ainda têm estudos relacionados a questões identitárias mundo afora. A virada material, à qual a autora se refere, está contida em uma questão maior de perfil fenomenológico e semiótico, ainda que não explícito: o foco atual na materialidade que anteriormente era atribuído sobretudo ao simbólico-cultural consiste na concessão de uma atenção maior à indexicalidade nas representações e na compenetração atual dos estudiosos de LIJ nos (potenciais) objetos dos signos (imediato/ dinâmico). O foco no elemento identitário, ainda que não despido de caráter simbólico, põe, assim, ênfase em questões metonímicas de pertencimento e contiguidade (fazer parte de). Paralelamente, a conjuntura de todo índice encapsular ícones, ou de a indexicalidade abranger a iconicidade, reside no fato de que a pertinência a um grupo também é definida pelas características similares compartilhadas pelos membros do grupo, ou pelo indivíduo-corpo e seu entorno, em processos de influenciação mútua. De algum modo, as marcas de pertinência a grupos, identidades e lugares estão evidenciadas nos corpos.

Além deste aspecto da corporeidade apontado por Nikolajeva, chama a atenção, em nosso país, embora não apenas nele, a atenção que vem sendo dedicada, desde o final do século passado mas com maior ênfase na atualidade, às pesquisas em LIJ a respeito da materialidade do livro infantil, as quais põem em relevo não apenas inevitáveis questões de terceiridade mais explícita (linguagens-interpretação-significação-comunicação), como a participação da linguagem do design em processos poéticos de representação-significação, mas também as de secundidade (existência bruta do livro em choque com o corpo-leitor) que sobrelevam a materialidade do livro em contato com a corporeidade do leitor e seus processos de fruição que vão muito além da percepção visual com seu tradicional caminho perceptivo olho-cérebro. Te- 
mos, agora, um foco maior no corpo que lê com todos os sentidos de que dispõe. Assim, neste âmbito segundo e de diálogos multissensoriais, encontramos também com especial destaque em pesquisas atuais de LIJ as questões concernentes à alteridade.

Se tomarmos, como exemplo, a abordagem do tema crianças com deficiência na perspectiva dos anos 1990, encontraremos um foco que privilegia os significados, interpretações, representações e lugares sociais simbólicos das pessoas com deficiência e do capacitismo em sociedade e suas representações na ficção; já na perspectiva apresentada por Nikolajeva como atual, veremos mais representadas as condições concretas e físicas (secundidade, indexicalidade) e as qualidades/características (iconicidade) de ser-se um corpo com deficiência. Essa leitura pode provocar uma comparação (secundidade por contrastação, primeiridade por foco em qualidades) resultando em identificação (graças à representatividade) ou em exercício de empatia diante da realidade outra (alteridade evocando conhecimento do outro e autoconhecimento, já no nível da interpretação-interpretantes-terceiridade).

À parte destas tendências destacadas por Nikolajeva e acima elencadas por mim de maneira esquemática e à guisa de resumo, além de meus próprios acréscimos, pode-se observar, ademais, certa constância em movimentos de reinterpretação (munidos de ímpeto revisionista) do cânone literário infantil e juvenil (literatura primária) e do arcabouço crítico que constitui seus estados-da-arte (literatura secundária), a partir de releituras do conjunto delimitado de obras que os compõem. Isso não vai de encontro ao que nos apresenta Nikolajeva mas, em vez disso, ao seu encontro. Isto porque a (re)consideração de questões até há pouco tidas como petrificadas ou monolíticas e inteiramente definidas por determinantes biológicos tende a reencará-las como construções sociais. Tais construções, como se sabe, vão-se modificando através dos diferentes tempos, lugares e contextos, clamando, segundo os que assim pensam, por revisões, questionamentos e (des)construções.

Deste modo, observo, como exemplo apropriado para ilustrar estas considerações, a recente (julho de 2021) chamada para submissão de artigos para o vindouro dossiê “Questioning the Canon: Rethinking the Golden Age of Children's Literature” do periódico Children's Literature Association Quarterly, com publicação prevista para o verão de 2023 no número 48.2 da supramencionada revista. Esse compêndio visará 
propor releituras de visões e posicionamentos acerca da convencionalmente denominada "Golden Age of Children's Literature" [Era de Ouro da Literatura Infantil], agora reinterpretada como um fenômeno local de países anglófonos outrora encarado como representando a literatura mundial, ou seja, que de algum modo tratou de excluir literatura produzida por indígenas, pessoas não brancas etc.

Assim sendo, e expandindo a natureza inclusiva das pesquisas hodiernas em LIJ, constantemente em busca de representatividade de minorias, o dossiê pretende auxiliar na mitigação de diversas lacunas concernentes à formação do cânone da LIJ.

Em contraste com estas observações, vemos como Kümmerling-Meibauer, na introdução de sua recente (2017) e extensa obra Klassiker der Kinder- und Jugendliteratur: Ein internationales Lexikon [Clássicos da Literatura Infantil e Juvenil: um dicionário internacional], pontua que a restrição da abrangência dessa obra à produção de 65 países tem essencialmente a ver com o fato de que, na maior parte dos países da Ásia e da África, não se teria formado, ainda, uma literatura infantil própria, ou não se poderia observar, até o presente, prelúdios da formação de uma literatura infantil sofisticada nesses territórios.

A partir da perspectiva dos estudiosos pertinentes aos ramos investigativos explorados por Nikolajeva (2016) em seu panorama, e nas suprarreferidas buscas dos pesquisadores que organizam o mencionado dossiê do periódico Children's Literature Association Quarterly, assistimos à convivência, de um lado, de visões mais tradicionais e arraigadas de cânone, assentadas em maneiras mais convencionais de abordagem crítica das produções literárias e culturais para crianças e jovens, com, do outro, perspectivas mais recentes que objetivam revisar essas noções e preencher lacunas na própria construção do cânone da LIJ que, pelo olhar do agora, parecem derivar de processos deliberados ou não suficientemente discutidos de exclusão e de elitismos. Pode-se supor, assim, que pesquisadores com esta segunda orientação talvez justificassem a ausência de representatividade de obras infantis africanas e asiáticas no dicionário de Kümmerling-Meibauer devido à escassez de registros de literatura oral ou, ainda, a uma presentemente criticada tradição de desprestígio e negligência de obras advindas dessas culturas assentada em hierarquizações históricas dos povos, territórios, culturas e corpos promovida desde o colonialismo. 
Assim, cumpre encontrar, no meio de tantas transformações pelas quais vem passando a cadeira acadêmica de LIJ, o espaço do ensaio de Bernheimer e da abordagem formal do conto de fadas.

\section{BERNHEIMER E O LEGADO DE LÜTHI E ZIPES}

Kate Bernheimer é uma escritora especialmente dedicada ao gênero conto de fadas, que exerce influência fundante em sua própria criação, além de editora e pesquisadora norte-americana. Sua obra ficcional, assentada em pesquisa, iniciou-se com a publicação de coletâneas de contos de fadas como Mirror, Mirror on the Wall (Doubleday, 2002) e Brothers and Beasts (Wayne State University Press, 2007). A partir disso, escreveu uma trilogia de romances baseados em contos de fadas russos, alemães e de origem iídiche, a saber, The Complete Tales of Lucy Gold (2011), The Complete Tales of Merry Gold (2006), e The Complete Tales of Ketzia Gold (2001), todos pela Fiction Collective 2, além da coletânea de contos Horse, Flower, Bird (Coffee House Press, 2010), entre diversos trabalhos de curadoria e editoração. Bernheimer é também autora de inúmeras e agudas análises críticas de contos de fadas de tipologia e etiologia diversas que encontram-se publicadas em diversas páginas web que veiculam suas contribuições. No item 6 deste texto apresentaremos, entretanto, a tradução de um ensaio crítico por ela publicado como capítulo de livro (BERNHEIMER, 2009).

Já no título de seu ensaio, a autora presta homenagem a um pesquisador fundamental no campo dos estudos críticos acerca do conto de fadas, Jack Zipes. Mais especificamente, a autora parafraseia o título de seu livro Fairy tale as myth, myth as fairy tale [O conto de fadas enquanto mito, o mito enquanto conto de fadas], de 1994. Embora o autor, nesse texto, no qual fartamente recupera o pensamento de Mircea Eliade, considere já de entrada diferença fundamental entre mito e conto de fadas, baseada, por sua vez, na função sagrada que se destaca junto ao primeiro, procura, ali, salientar-lhes as similitudes. Apesar da homenagem, Bernheimer não exatamente captura, em seu texto, o rumo das ideias de Zipes sobre a relação entre mito e conto de fadas. Em vez disso, dedica-se a contemporanizar e esquematizar, de modo prá- 
tico e estruturado, conceitos fundamentais explorados por Max Lüthi em suas obras baseadas na abordagem fenomenológica (KÜMMERLING-MEIBAUER, 1991) do gênero ao qual se dedicam acerca da estrutura formal dessas narrativas (LÜTHI, 1947, 1962a e 1962b, entre outras).

Logo no início de seu ensaio, Bernheimer permite-se iniciar o texto de maneira a ser considerada pouco convencional a partir de um enquadramento acadêmico: "Nossa, como amo contos de fadas". Em seguida, afirma que textos desse gênero representam "tudo" para ela. Essa imiscuidade das emoções na introdução de seu texto deve-se ao caráter sui generis deste escrito, que se pretende a expressão do depoimento de uma artista e escritora (embora não deixe, por isso, de ser uma acadêmica) acerca de um gênero que a motiva, inspira e fascina, sem a pretensão anunciada de consistir em um artigo que persiga corresponder a convenções e formalidades. Apesar disso, o anúncio dessas emoções nada mais faz além de prenunciar sua motivação para dedicar-se ao tema, uma vez que aquilo que é enunciado adiante possui notório e iminente valor científico, já que, com base em fundamentação teórica devidamente anunciada, conduz-nos à apreciação de um processo de reconhecimento e categorização de fenômenos a partir de luz própria, o que lhe permite propor, ainda, uma taxonomia singular que visa nomear os recortes fenomenológicos empreendidos e suas subsequentes descrições e exemplificações. Buscando o estabelecimento de um frutífero diálogo com o leitor, frequentemente dirige-se a ele, ao longo do ensaio, em segunda pessoa.

Ao auxiliar-nos na captura de momentos ou constituintes intrínsecos ao conto de fadas, por ela denominados planicidade ("flatness"), abstração ("abstraction"), lógica intuitiva ("intuitive logic") e magia naturalizada ("normalized magic"), a autora nos apresenta as bases mesmas do funcionamento dos contos de fadas que são, por sua vez, as razões pelas quais eles evocam a criação de tão grande número de adaptações, recriações e transposições de seu imaginário a outras linguagens artísticas.

Deste modo, textos críticos de vertente formal, como o de Bernheimer, que ora apresentamos ao leitor, desta feita transposto ao português brasileiro, não se encontram em disputa com os focos correspondentes aos demais eixos do sistema literário nem com as tendências das mais contemporâneas pesquisas em LIJ. Ao contrário, unem-se a elas e as estimulam, oferecendo-lhes estofo sustentador. 


\section{REFERÊNCIAS}

BERNHEIMER, K. Fairy tale is form, form is fairy tale. In: ALLISON, D.; BENDER, A.; BERNHEIMER, K.; SHEPARD, J. (Orgs.). The writer's notebook: Craft essays from tin house. Tin House Books, p. 61-73, 2009.

CANDIDO, Antonio. Formação da literatura brasileira: momentos decisivos (2 volumes). 9a. edição. Belo Horizonte: Itatiaia, 2006 [1975].

COSSON, Rildo. Literatura infantil em uma sociedade pós-literária: a dupla morfologia de um sistema cultural em movimento. Pro-Posições, n. 27 (2), p. 47-66, Mai-Ago 2016.

FERRARA, Lucrécia. O texto estranho. São Paulo: Perspectiva, 1978.

KÜMMERLING-MEIBAUER, Bettina. Die Kunstmärchen von Hofmannsthal, Musil und Döblin. Colônia/Weimar/Viena: Böhlau, 1991.

KÜMMERLING-MEIBAUER, Bettina. Klassiker der Kinder- und Jugendliteratur: Ein internationales Lexikon. Band 1: A-K; Band 2: L-Z. Heidelberg: JB Metzler, 2017.

LAJOLO, Marisa. Preconceito e intolerância em Caçadas de Pedrinho. Revista Emília, 01.07.2011. Disponível em: https://revistaemilia.com.br/preconceito-e-intolerancia-em-cacadas-de-pedrinho/ . Acesso em: 13.07.2021.

LÜTHI, Max. Das europäische Volksmärchen, Form und Wesen; Eine literaturwissenschaftliche Darstellung. Berna: A. Francke, 1947.

LÜTHI, Max. Es war einmal; Vom Wesen des Volksmärchens. Göttingen: Vandenhoeck \& Ruprecht, 1962a.

LÜTHI, Max. Märchen. Stuttgart: Metzler, 1962b.

NIKOLAJEVA, Maria. Recent trends in children's literature research: return to the body. International Research in Children's Literature, Volume 9 Issue 2, Page 132-145, Nov. 2016.

ZIPES, Jack. Fairy tale as myth, myth as fairy tale. Lexington: University Press of Kentucky, 1994. 


\section{TRADUÇÃO COMENTADA: \\ "CONTO DE FADAS É FORMA, FORMA É CONTO DE FADAS"1}

Kate Bernheimer ${ }^{2}$ Tradução por André Luiz Ming Garcia

1 Nota da autora: “Este trabalho é uma homenagem ao influente estudo de Jack Zipes Fairy Tale as Myth/Myth as Fairy Tale (Lexington: University Press of Kentucky, 1994)".

2 Nota do tradutor: Este texto contém notas de rodapé com comentários do tradutor, sinalizadas numericamente, e quatro notas de fim, inseridas pela própria autora no corpo do texto original em inglês, aqui indicadas com letras, de (A) a (D).

3 Bacharel, licenciado, mestre e doutorando em Letras pela Universidade de São Paulo. 
"O conto de fadas, que até hoje é o primeiro tutor das crianças porque um dia foi o primeiro tutor da humanidade, vive secretamente na história. O primeiro e verdadeiro contador de histórias é, e continuará a ser, o contador de contos de fadas".

-Walter Benjamin

"Se durante um certo período da minha carreira de escritor sent-mei atraído por contos populares e contos de fadas, isso não foi o resultado de uma lealdade a uma tradição étnica... nem o resultado de uma nostalgia por coisas que li quando criança. Foi mais por causa do meu interesse no estilo e na estrutura, na economia, ritmo e lógica dura com os quais eles são contados".

-Ítalo Calvino

"Nossa cultura é altamente individualizada, com uma grande fé na obra de arte como sendo única e no artista como sendo original, um criador divino e inspirado de itens absolutamente únicos. Mas contos de fadas não são assim, nem assim o são seus criadores. Quem inventou as almôndegas? Em que país? Existe uma receita definitiva para a sopa de batatas? Pense em termos de artes domésticas. É assim que eu faço sopa de batatas."'

-Angela Carter

Nossa, como eu amo contos de fadas. Com este ensaio, gostaria de transmitir o que os contos de fadas significam para mim como artista: no caso, tudo (sempre, desde que eu era criança, tenho sido mais feliz vivendo no contexto de uma história. Isso em si já é um conto de fadas). Eu também gostaria de desmistificar a ideia de que os contos de fadas seriam úteis apenas para escritores de fantasia ou fabulismo ${ }^{4}$ Eu gostaria de comemorar a forma lúcida desses contos. E eu gostaria de revelar como técnicas específicas dos contos de fadas cruzam fronteiras estilísticas. Ao passo em que a interpretação de contos de fadas constitui um caminho muito percorrido entre escritores, as técnicas de contos de fadas, por sua vez, permanecem pouco identificadas e apreciadas.

“O prazer dos contos de fadas", escreve o estudioso suíço Max Lüthi, "reside

4 Nota do tradutor: forma literária de realismo mágico. 
em sua forma". Eu me encontro cada vez mais devota do prazer oriundo da forma em geral, e da forma dos contos de fadas de modo específico, e por isso estou ansiosa por compartilhar aqui o que as técnicas dos contos de fadas fizeram pela minha escrita e o que também podem fazer pela sua. Os contos de fadas oferecem um caminho para o êxtase - o êxtase da forma - onde o leitor ou escritor encontra um lar ao mesmo tempo feliz e terrível.

Conto de fadas. Este termo traz à mente uma forma única que ainda reconhecemos e usamos mesmo após muitos séculos de manipulação de suas discretas técnicas. A forma sobrevive à mutação. Isso é também aplicável a uma ampla gama de estilos e formas narrativas. Contos de fadas atraem magneticamente escritores que se identificam como realistas, junto com surrealistas e dadaístas e modernistas e existencialistas e autores de ficção científica e fabulistas (para não mencionar escritores de novelas românticas e autores de cartões de felicitações e redatores de manchetes de tablóides). No entanto, em conversas entre escritores, a discussão de sua forma tão clássica é muitas vezes eclipsada por uma apreciação de seus óbvios momentos selvagens e estranhos. $\mathrm{O}$ fato de muitos escritores celebrarem o cosmos escuro e fantástico dos contos de fadas já é em si algo incrível, mas eu também gostaria de assistir a um crescente reconhecimento de sua destreza artística.

Você não precisa nem mesmo ter qualquer interesse consciente em contos de fadas para apreciar o efeito que eles exercem sobre você. Os contos de fadas afetam-nos a todos nós: como são onipresentes! Os escritores com quem falo ficam frequentemente surpresos ao descobrir que o que estão fazendo advém de uma linhagem formal dos contos de fadas. Às vezes, nossas conversas os levam a incorporar novos motivos em seu trabalho, ou a intensificar outros, em homenagem direta aos contos de fadas. No entanto, uma subestimação crítica do teor artístico dos contos de fadas conduz, por vezes, à interpretação errônea desses lindos e deliberados gestos como sendo acidentes infelizes ou diminuições do grau de verossimilhança do trabalho que se tem em mãos (existem muitas razões para essa subestimação, é claro, e são razões estranhas e tristes. Parte do problema consiste em que muitas interpretações de contos de fadas estão carregadas de clichês. Mas esse é um tema para outro ensaio. Por enquanto, vamos simplesmente dizer que sua associação com as mulheres e as 
crianças e com as histórias de ninar talvez tenham desempenhado um papel importante. Além disso, as meninas-lobo simplesmente entram em pânico).

Então: em vez de dedicarmo-nos a entender como os contos de fadas foram depreciados, vamos, em vez disso, celebrar sua forma. Para fazê-lo, gostaria de me concentrar em quatro elementos dos contos de fadas tradicionais: planicidade, abstração, lógica intuitiva e magia naturalizada ${ }^{5}$. Eu acredito que esses componentes formais (embora existam outros [A]) compreendem a dura lógica dos contos a que Italo Calvino se refere em uma das epígrafes deste ensaio. Muitos autores que amam contos de fadas referem-se a esta dureza como sendo uma contribuição para o seu amor pela forma - mas eu gostaria de dar um passo adiante e examinar esses quatro componentes conforme se relacionam especificamente com o espectro redutor da escrita convencional e de vanguarda. Ou seja, esses quatro componentes técnicos dos contos de fadas tradicionais podem ser encontrados em diversos graus nos estilos mais comumente citados de escrita e, portanto, uma maior compreensão das técnicas de contos de fadas pode ajudar a resolver os dissensos infelizes que às vezes surgem entre os chamados escritores e críticos de vanguarda e mainstream (e, apesar de uma afeição emergente pelo fabulismo, acho que nós todos sabemos quem tem o poder mais óbvio neste dissenso - os contos de fadas que, com sua predileção pelos oprimidos, podem ajudar a interromper esta hierarquia prejudicial).

Outra premissa deste ensaio é que, assim como Sylvia Plath, poemas (e, de

5 Nota do tradutor: No texto original, o termo cunhado por Bernheimer é "normalized magic", cuja tradução mais literal ao português seria "magia normalizada”. Minha opção, contudo, por transpor o termo ao português como "magia naturalizada" deve-se não apenas ao fato de que aquilo que se torna normal igualmente se torna natural, mas também pelo fato de que a normalização da magia no conto de fadas e nos contos maravilhosos, de forma geral, implica sua equiparação com a natureza no nível da exegese própria do conto, sendo a natureza, nessa maneira para nós nova, ampla e perpassada por magia, elemento essencial para a forma dessas narrativas. Reside, aqui, a questão-chave no entendimento dos gêneros do maravilhoso: a natureza do e no conto de fadas parece-nos, a nós, e apenas se lermos esses textos de maneira distante da devida, estranha. Lidos da maneira que aqui se considera mais experimentada, aquela própria daqueles que já tiveram contato com diversos contos desse tipo e que, ainda que intuitivamente, aprenderam a entendê-los em sua lógica, eles ostentam a mais normal das naturezas: a única que se pode imaginar em seu seio e da qual se constitui. 
fato, ela era uma poeta muito interessada em contos de fadas) foram analisados muito mais por seu significado do que por sua forma, e o mesmo acontece com os contos de fadas. Eu estudo a interpretação de significados nos contos de fadas - há uma pilha de livros acadêmicos sobre a minha mesa em que estão enterrados meus livros de contos de fadas já bem gastos - e eu aplico de maneiras complexas o que aprendi na minha experiência com editoração, ensino e redação. Aprender a história dos contos de fadas é aprender a história do mito, da impressão, da infância, da alfabetização, da violência, da perda, da psicologia, do ensino, da ilustração, da autoria, da ecologia, de gênero e mais. Meus três primeiros romances - embora escassos em palavras, como de fato são (um amigo brinca que meus romances inteiros contêm aproximadamente o mesmo número de palavras que qualquer capítulo de $u m$ dos seus romances) - tente ser sobre isso tudo empregando técnicas de contos de fadas.

Além disso, meu estudo de técnicas de contos de fadas oferece um prazer diferente, que me é muito íntimo, enquanto trabalho em meus romances: o prazer da linguagem enquanto ela molda a história. Os contos vivem dentro de mim, ao que parece, e isso é adorável. Os contos de fadas são os esqueletos da história, talvez. Lê-los muitas vezes produz uma inquietante sensação - uma familiaridade corrosiva - aquela consciência reconfortante, mas sobrenatural de estar-se a viver dentro de uma história.

Leitores de coleções de contos de fadas, como leitores de - bem - livros, sabem por meio dessas técnicas que eles estão dentro das histórias, perdidos ou imaginados ou inventados lá dentro.

Suponho que quase todo mundo se lembra de um conto de fadas dos tempos de infância, mas, em todo caso, aqui temos um chamado "O botão de rosa" (conto alemão, traduzido por Ralph Manheim) para nos ajudar-nos a entrar em forma:

Era uma vez uma mulher pobre que tinha duas menininhas. A mais jovem era enviada à floresta todos os dias para colher lenha. Certa vez, quando ela já havia percorrido um longo caminho antes de encontrar qualquer lenha, apareceu uma linda criancinha que a ajudou a pegar a lenha e levou-a para ela até sua. Então, em um piscar de olhos, ela desapareceu. A menina contou os fatos à mãe, mas a mãe não quis acreditar. Então, um dia, ela trouxe para casa um 
botão de rosa e disse à sua mãe que a linda criança o tinha dado a ela e dito que viria novamente quando o botão de rosa se abrisse. A mãe colocou o botão de rosa na água. Certa manhã, a menina não se levantou da cama. A mãe foi e encontrou a criança morta, mas com uma aparência adorável. $O$ botão de rosa tinha-se aberto naquela mesma manhã.

É claro que todos nós conhecemos a abertura - "Era uma vez" - a partir daí, a primeira coisa que você sempre sabe sobre um conto de fadas é que você está dentro dele. Imediatamente, ele anuncia ser uma forma e que você está dentro dessa forma.

Além do fato de achar que esta é uma das mais perfeitas histórias do mundo, ela ainda funciona bem para apresentar as quatro técnicas do conto de fadas que mencionei anteriormente. Essas técnicas mostraram-se presentes, de algum modo, em quase todos os contos de fadas literários ao longo de centenas de anos, desde o século XVII até o presente, ao redor do mundo e através de vários estilos. Podemos encontrá-las em uma narrativa pós-moderna e fragmentada de Donald Barthelme ("The Glass Mountain"); em uma narrativa linear cheia de suspense de A. S. Byatt ("The Thing in the Forest"); em um poema psicológico subversivo de Rita Dove ("Beauty and the Beast"); e em um sensível e minimalista poema de Fanny Howe ("Forty Days"). Poderíamos citar centenas de diversas obras de centenas de diversos escritores nas quais podemos facilmente encontrar tropos e técnicas básicas de contos de fadas.

Vamos, então, começar com a planicidade. Personagens em um conto de fadas são sempre planas (quer seja Chapeuzinho Vermelho, a Madrasta, o Ouriço ou a Fera). Em “O botão de rosa”, temos uma mãe e duas filhas, uma identificada apenas como "a mais jovem" e uma descartada após a primeira frase. Personagens de contos de fadas são silhuetas, mencionadas simplesmente porque estão lá ${ }^{6}$. A elas não são atribuídas muitas emoções - talvez uma, como feliz ou triste - e estas não estão em conflito psi-

6 Nota do tradutor: Vladimir Propp, em Morfologia do conto maravilhoso, focalizava a importância das personagens nessas narrativas sobretudo a partir das funções que desempenham em prol do andamento da narrativa, ou do encadeamento linear da sucessão de peripécias. Essa ênfase em sua funcionalidade em textos onde se prioriza a narração explica parcialmente a negligência do gesto de descrevê-las ou mesmo desenvolvê-las com maior profundidade física ou psíquica. 
cológico. Em um conto de fadas tradicional, uma criança que escapara de um avanço incestuoso não se tornou um adulto neurótico. Esta ausência de profundidade, esta planicidade, viola uma regra técnica frequentemente ensinada aos escritores no início das aulas de redação: que a profundidade psicológica de um personagem é crucial para uma história. Em um conto de fadas, no entanto, essa planicidade funciona lindamente; permite profundidade de resposta no leitor (eu tenho escrito por alguns anos sobre como as técnicas de contos de fadas também são proeminentes em muitas obras de artes visuais contemporâneas. Um bom exemplo de planicidade de conto de fadas em artes visuais é o trabalho de Kara Walker. Walker usa recortes vitorianos ampliados, incorporando imagens folclóricas em suas angustiantes e comoventes narrativas de identidade, gênero e raça).

A planicidade, é claro, combina com a técnica da abstração. Os contos de fadas dependem da abstração para que gerem seu efeito. Não muitos detalhes ilustrativos e descritivos em particular são fornecidos. As coisas nos contos de fadas são descritas com linguagem aberta: adorável. Morto. Bela. Em “O botão de rosa”, não há explicação de como ou até que ponto ou de que modo as crianças são amáveis ou bonitas. Aqui temos outra violação muito emocionante, a dessa regra "mostre, não diga" de vocês, pessoal mais velho. Os contos de fadas contam; eles não mostram com frequência. $\mathrm{Eu}$, muito naturalmente, como escritora, estou inclinada a essa ausência.

Curiosamente, se você olhar para os contos de fadas tradicionais, também encontrará um uso muito limitado de cor e uma forte dependência de coisas que são metálicas ou de vidro (B). Em muitas versões literárias de "Chapeuzinho Vermelho", você encontrará a cor de sua capinha descrita e, muitas vezes, que os dentes do lobo são brancos. Vermelho e branco (veja também a história alemã "Branca de Neve e Rosa-Vermelha" e o uso delicado e gentil desse motivo no complexo romance contemporâneo de Kathryn Davis The Walking Tour). Mas não há muitas outras cores. $\mathrm{O}$ lobo não é descrito como marrom; a floresta não é descrita como exuberantemente verde. As imagens em um conto de fadas são muito isoladas, muito específicas. Tão precisas. Tão enganosamente simples.

Para remendar a história, os contos de fadas fazem uso do que chamo de lógica intuitiva, uma espécie de sentido sem sentido. A linguagem dos contos de fadas 
tradicionais nos diz que primeiro aconteceu isso e depois aconteceu aquilo. Nunca há uma explicação do porquê. Na verdade, a pergunta por que não costuma surgir. As coisas geralmente acontecem em um conto de fadas quando elas precisam acontecer, mas outras coisas acontecem que não têm relevância além do efeito de linguagem. Isso não está logicamente conectado àquilo, exceto por sintaxe, por proximidade narrativa. Em “O botão de rosa”, não há razão para pensarmos que a criança na floresta tenha algo que ver com a morte da menina. Da mesma forma, a flor se abrindo após sua morte. E aquela filha mais velha - o que aconteceu com ela? Você pode imaginar enviar uma história para um oficina de redação em que o primeiro parágrafo apresenta dois irmãos, mas um dos irmãos nunca mais é mencionado? ${ }^{7}$

Em um conto de fadas, dentro dessa desconexão lírica, reside uma história que penetra e assombra você profundamente, eu acho. Você não duvida de que um conto de fadas aconteceu exatamente como foi escrito. Isso pode explicar o apelido de contos de fadas como "just-so stories" ["histórias que são assim porque sim"] (algo às vezes empregado para enaltecê-las, às vezes para depreciá-las).

No que é considerada a versão literária mais antiga de "Chapeuzinho Vermelho", intitulada "A história da avó", a menina entra na cabana da avó e um gato em uma prateleira a vê e diz: "Você é uma vagabunda se beber o sangue da avó!" [C]. A menina mal fica surpresa com o gato xingador, sem falar da sua linguagem obscena, nem mesmo está preocupada com o fato de que o sangue de sua avó possa estar em jogo. Como a menina, o leitor passa facilmente para a próxima frase, quando a menina se aproxima do lobo na cama da avó e começa a fazer um striptease. Chocante, talvez, mas, quando você lê a história, o teor poético é, ainda assim, notável e belo.

Apesar de sua reputação de narrativas baseadas em enredos, contos de fadas mostram ser extremamente associativos quando você começa a descosturá-los. Eles utilizam uma lógica intuitiva.

7 Nota do tradutor: Em Lüthi (1947), este elemento específico da lógica intuitiva é abordado como “motivos truncados" ou, em certos casos, como os correlacionados "motivos cegos", encarados, pelo estudioso, como característicos da estética do gênero e talvez derivados de seu caráter espontâneo e de sua origem oral. 
Em “O botão de rosa”, a filha mais velha é simplesmente um substantivo; no entanto, ela existe na história, existiu lá por muito tempo. Ela é representada com tal segurança sintática que parece predestinada; a narrativa nunca levanta a questão de seu desaparecimento. Os detalhes em um conto de fadas existem isolados do que é comumente chamado de "enredo", mas têm o efeito de fazer tudo parecer inevitável, correto. De certa forma, isso é muito pós-moderno - e não ao contrário do que acontece sintaticamente em algum tipo de poesia que é chamada "poesia da linguagem". No entanto, a história também parece mimética, não é? ( $\mathrm{O}$ espectro estilístico entra em colapso para mim - e revela que o erroneamente rotulado "não-realismo" é uma das nossas formas mais antigas).

E, claro, essa qualidade associativa também é uma espécie de violação, uma violação da regra de que as coisas devam fazer sentido. Vários contos de fadas dependem da relação sentida das palavras com a história - a arte de colocar palavras juntas em uma ordem estranha, mas maravilhosa, que simplesmente parece correta, não importa o quão difícil seja pegá-las separadamente e tentar montá-las de novo com a lógica cotidiana. Um conto de fadas é um Humpty Dumpty ${ }^{8}$.

A técnica final que discutirei aqui é a magia naturalizada. O mundo natural em um conto de fadas é um mundo mágico. O dia-a-dia colide com o maravilhoso. Em um conto de fadas tradicional não há necessidade de um portal. O encantamento não é surpreendente. A magia é o normal.

Em “O botão de rosa”, nossa querida garotinha que está prestes a morrer não se assusta com o aparecimento de uma criança que depois desaparece. A mãe não acredita na filha, mas não se assusta. No conto de fadas, o mágico e o real coexistem - trata-se de uma técnica. Isso é uma arte.

Em As aventuras de Alice no País das Maravilhas, de Lewis Carroll, Alice não está preocupada com o fato de que que um bebê que ela carrega se transforme em um porco: na verdade, ela simplesmente colocou "a criaturinha no chão e se sentiu bastante aliviada ao vê-la trotar silenciosamente para a floresta" [D].

8 Nota do tradutor: Emblemática personagem da literatura infantil, que consiste em um ovo antropomórfico, presente em contos de fadas e outras narrativas influentes do cânone da LIJ, entre elas Alice através do espelho, de Lewis Carroll. 
Da mesma forma, no filme de 1946 de Jean Cocteau, La Belle et La Bête, a Bela não tem medo de a Fera ser uma fera - e não, digamos, um humano - ela está com medo simplesmente porque a aparência dele a assusta. É o choque de sua imagem que a assusta, não sua não-humanidade, ou seja - não a magia. Lüthi chama esse efeito de "choque de beleza" em contos de fadas. Considere como na maioria das versões de "Chapeuzinho Vermelho" a menina não tem medo de que um lobo fale com ela no bosque. Magia naturalizada. Você pode chamar isso de "suspensão da descrença" se quiser, mas eu prefiro a ideia de que os contos de fadas não exigem suspensão por parte do leitor; eles já estão suspensos, expandidos, extasiados com a magia naturalizada. Em contos de fadas não há grande alvoroço devido aos acontecimentos fantásticos.

Com sua planicidade, abstração, lógica intuitiva e magia naturalizada, os contos de fadas têm a chave da porta fortemente trancada entre o chamado realismo e o não-realismo, a convenção e o experimentalismo, a psicologia e a abstração. Uma chave para quem os vê como binários, portanto. Vistas pelas lentes dos contos de fadas, muitas obras podem ser entendidas como técnicas de compartilhamento de formas literárias.

Autores contemporâneos tão aparentemente díspares em termos de textura quanto Robert Coover e A. S. Byatt, Haruki Murakami e Stacey Levine, Rikki Ducornet e Alice Hoffman, Ben Marcus e Donna Tartt, Gregory Maguire e Joy Williams empregam formas e técnicas que têm suas raízes em contos de fadas - seja conscientemente por parte desses autores ou não - e estão juntos no caminho de agulhas e alfinetes 9 da floresta. No trabalho de todos esses escritores, pode-se identificar os padrões de planicidade, abstração, lógica intuitiva e magia naturalizada. O modo como cada autor se expande e contrai a partir desse modelo formal é o que faz dele um artista. Todo escritor é como uma boneca às avessas que, de um lado, é Chapeuzinho Vermelho e, do outro, é o Lobo ou, de um lado, está um Menino e, do outro, um Corvo e um Caixão ${ }^{10}$. As técnicas tradicionais dos contos de fadas - identificáveis, nomeadas - renascem nas diferentes maneiras através das quais todos nós contamos histórias.

9 Nota do tradutor: Referência a motivos presentes em versões primevas do conto "Chapeuzinho Vermelho" prévias ao seu registro escrito tanto por Charles Perrault quanto pelos irmãos Grimm.

10 Nota do tradutor: Referência ao conto “Os doze irmãos" dos irmãos Grimm. 
Se acaso reconhecermos o prazer na forma que pode ser obtido a partir dos contos de fadas, talvez sejamos capazes de ir além de uma discussão sobre quem tem mais poder de reivindicação do estilo "realista" ou do estilo clássico em letras contemporâneas. Uma maior apreciação das técnicas dos contos de fadas apenas estabelece uma apreciação mútua entre escritores das chamadas tradições mainstream e de vanguarda, mas também, diria eu, conecta-nos todos no ato de viver. Eu acredito de verdade.

No entanto, uma subestimação contínua das técnicas dos contos de fadas e sua influência em centenas de anos de escrita conduzirão, em vez disso, ao seu desaparecimento. Além disso, isso levará alguns maravilhosos livros a serem desacreditados por alguns críticos influentes como sendo difíceis ou obscuros ou com aparência irreal (aqui eu ofereço a sugestão de que você retorne a alguns livros que rejeitou com base nisso, se é que alguma vez você o fez, e considere-os novamente através de uma lente de conto de fadas. Ou, se você está escrevendo este tipo de livro, tome coragem aqui).

Muitas vezes, quando um motivo de conto de fadas é reconhecido em uma história ou livro, esse trabalho é casualmente referenciado como uma recontagem ou adaptação, apenas grosso modo vistos como contos de fadas, e às vezes até mesmo chamados de "apenas um conto de fadas". Eu não gosto da hierarquização de "isto é mais realista do que isso e, portanto, é mais valioso do que aquilo". Mas muitos desses livros chamados de não realistas ou fantásticos devem muito à forma clássica - e uma das formas mais clássicas do mundo são os contos de fadas.

Finalmente - e muito infelizmente -, junto com a rejeição dos contos de fadas, encontramos, por vezes, uma rejeição da própria forma.

Emily Dickinson, que também amava contos de fadas, sabia da forma e da sua importância:

Depois de muita dor, um sentimento formal vem -

Os Nervos se assentam cerimoniosos, como Tumbas -

As duras questões do Coração: era Ele, que tédio,

E Ontem, ou Séculos antes?

Os Pés, mecânicos, giram -

De Chão, ou Ar, or Deveria - 
Um Caminho de madeira

Crescido apesar de tudo,

Um contentamento de Quartzo, como uma pedra -

Esta é a Hora de Chumbo

Lembrada, caso Sobrevivida,

Como pessoas Congeladas, recolhe a Neve -

Primeiro-Susto ${ }^{11}$ - então Estupefação- então o desapego- ${ }^{12}$

Centenas de anos, madeira, chumbo, pedra, reminiscência, estupor, desapego. Os padrões estão de pernas para o ar nas mãos de Dickinson, mas nós reconhecemos os motivos, e ela os costura em uma forma que brilha, sensacional e familiar ao mesmo tempo.

O conto de fadas é forma, forma é conto de fadas.

Vivam os contos de fadas.

Viva a forma.

11 Aqui, não é possível reproduzir com um vocábulo português a polissememia do substantivo "chill" de contemplação pertinente no poema original em inglês: "resfriado", mas também "relaxamento", "descontração", "calma", ou de suas possibilidades verbais como "gelar" ou "descontrair" ou adjeticas como "assustador" ou "que causa frio".

12 Tradução nossa. Poema original de Dickinson assim como reproduzido no ensaio de Bernheimer: "After great pain, a formal feeling comes-

The Nerves sit ceremonious, like Tombs-

The stiff Heart questions was it He, that bore,

And Yesterday, or Centuries before?

The Feet, mechanical, go round-

Of Ground, or Air, or Ought-

A Wooden way

Regardless grown,

A Quartz contentment, like a stone-

This is the Hour of Lead

Remembered, if outlived,

As Freezing persons, recollect the Snow-

First_CChill- then Stupor - then the letting go-" 


\section{NOTAS DA AUTORA:}

[A] Para uma discussão sobre os elementos formais dos contos folclóricos europeus tradicionais, indico a qualquer leitor interessado os livros surpreendentes, repetitivos e poéticos de Lüthi. Seus estudos formais de contos populares europeus fornecem um ponto de partida não só para o meu trabalho crítico, mas também para a minha ficção.

[B] A. S. Byatt escreveu um ensaio maravilhoso sobre isso chamado "Ice Snow, Glass" para Mirror, Mirror on the Wall: Women Writers Explore Their Favorite Fairy Tales (Nova York: Anchor/Vintage, 1998), que também aparece em sua coleção On History and Stories: Selected Essays (Cambridge: Harvard University Press, 2002).

[C] Veja-se uma excelente tradução de Maria Tatar em The Classic Fairy Tales: A Norton Critical Edition (Nova York: W.W. Norton, 1998).

[D] E sim, este famoso romance de contos de fadas emprega, sim, portais - é como Carroll faz sopa de batata. Os escritores amplificam e minimizam, arremessam e acumulam aquelas técnicas de contos de fadas que intuitivamente os atraem.

A tradução deste ensaio foi expressamente autorizada para publicação no Brasil pela autora, Kate Bernheimer, detentora dos direitos da publicação original, ao tradutor André Luiz Ming Garcia e ao periódico Literartes.

O tradutor expressa à autora seus mais profundos agradecimentos. 